
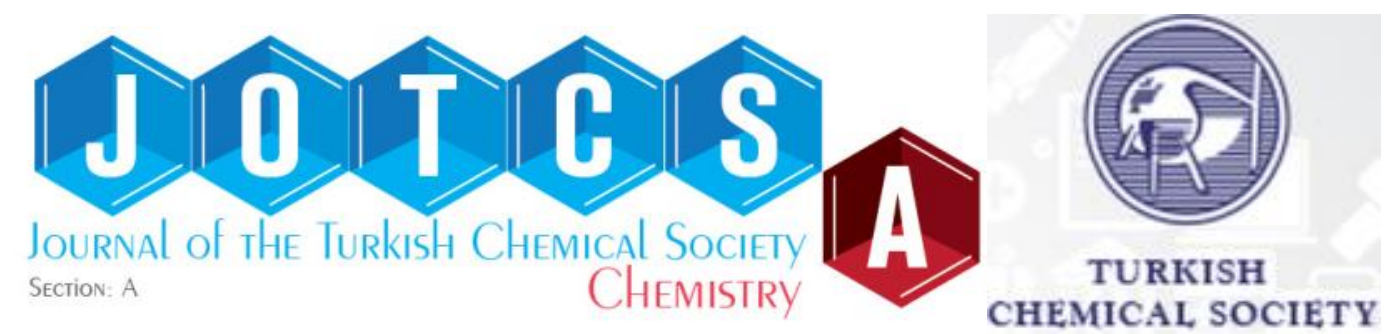

\title{
Multi-Walled Carbon Nanotube Reinforced Polyimide Composites
}

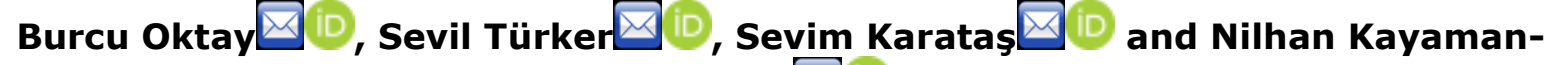 \\ Apohan $\triangle$ D $*$ \\ Marmara University, Department of Chemistry, 34722 Istanbul, Turkey
}

\begin{abstract}
Polyimides have a wide range of uses such as aeronautical applications of fuel cells, optics and electronic materials industry due to their outstanding thermal, mechanical and chemical properties. In this study, it was aimed to prepare composite polyimide films with amine-tethered multi-walled-carbon nanotubes (MWCNT). Firstly, to produce amine functional groups onto the surface of MWNCTs, MWCNTs were reacted with $\mathrm{H}_{2} \mathrm{SO}_{4} / \mathrm{HNO}_{3}$, thionyl chloride and ethylenediamine. Then polyamic acid solution was prepared from 3',4,4'-benzophenone tetracarboxylic dianhydride (BTDA) and, 4'oxydianiline (ODA). The functionalized carbon nanotube was added to the PAA solutions with certain amounts $(1,3,4,5$ and 6 wt. \% followed by stepwise thermal imidization. The thermal stability of the composite polyimide films were enhanced with addition of modified-carbon nanotube due to covalent interaction between polyimide based matrix and modified-carbon nanotube as a result of the imidization reaction. The addition of MWCNT increased the Tg of the BTDA-ODA-6\% MWCNTs polymide film from 275 to 304 ${ }^{\circ} \mathrm{C}$ with respect to the BTDA-ODA polyimide film. In addition, the mechanical properties of the films were improved. While the modulus of BTDA-ODA film was found as $743 \mathrm{MPa}$, with the introduction of MWCNT the modulus of BTDA-ODA- $6 \%$ MWCNTs was increased up to $1119 \mathrm{MPa}$.
\end{abstract}

Keywords: Polyimide, carbon nanotube, nanocomposite.

Submitted: October 18, 2017. Accepted: January 12, 2018.

Cite this: Oktay B, Türker S, Karataş S, Kayaman-Apohan N. Multi-Walled Carbon Nanotube Reinforced Polyimide Composites. JOTCSA. 2018;5(1):283-94.

DOI: http://dx.doi.org/10.18596/jotcsa.345015.

*Corresponding author. E-mail: napohan@marmara.edu.tr. Tel:+90 2163479641. Fax: +902163478783 . 


\section{INTRODUCTION}

Multi-walled and single-walled carbon nanotubes (MWCNTs and SWCNTs) have superior chemical, electrical, and thermal performance (1). Despite their extraordinary properties, dispersion of carbon nanotubes into a polymer matrix is limited because of their hydrophobic character. To overcome this problem, the covalent and non-covalent chemical modifications of carbon nanotubes should be carried out (2).

Covalent chemical modification of CNTs allows a fine dispersion within a polymer matrix. Generally, the carboxylic acid or hydroxyl groups are created on the CNT surface by treatment with sulfuric and nitric acid. The functional groups make further reactions of carbon nanotubes possible $(3,4)$.

Polyimides are a class of organic compounds that have received much attention owing to their excellent properties, such as superior thermal stability, mechanical properties and good chemical resistance (5). In addition, the composites can be used in advanced microelectronics and aerospace technologies due to their flexibility and radiation resistant properties (6). In recent years, a great amount of research has focused on the carbon nanotube/polyimide nanocomposites, to improve the properties of the polyimides. Incorporation of carbon nanotubes in polyimides has been shown to remarkably improve the mechanical and thermal properties of the resulting composites. Park et al. prepared carbon nanotube containing polyimide composites by in situ polymerization (7). Zhu et al. investigated the effect of carbon nanotubes on mechanical and electrical properties of the composites. The results showed that the composites containing carbon nanotubes had a higher tensile strength with good electrical properties (8). So et al. investigated the effect of carbon nanotubes on the morphological, mechanical, and electrical properties of MWNT-reinforced polyimides (9).

Non-covalent and covalent surface modifications have been used for functionalization of CNTs. Although, covalent surface modification can be better controlled to produce more stable nanomaterials (10). Commonly, the first step in this method is to incorporate carboxylic acid groups. In a second step, the carboxylic acid groups activated with thionyl chloride $\left(\mathrm{SOCl}_{2}\right)$ and then covalently attaching any molecule that contains a free-amine group such as ethylene diamine (11-14).

In this study, we focused on the modification of MWCNTs and the preparation of functionalized MWCNTs/polyimide composite films. Amine-tethered MWCNTs (MWCNTs$\mathrm{NH}_{2}$ ) were prepared by three step reactions. Firstly, MWCNTs were oxidized by a mixture 
of $\mathrm{H}_{2} \mathrm{SO}_{4}$ and $\mathrm{HNO}_{3}$, to produce surface carboxyl groups. Then, the $\mathrm{COOH}$ groups of MWCNTs were substituted with thionyl chloride and the resulting product was further reacted with ethylenediamine. Polyamic acid solutions were prepared by an in situ polymerization reaction from 3,3',4,4'-benzophenone tetracarboxylic dianhydride" (BTDA), 4,4'-oxydianiline (ODA) and various ratios of MWCNTs- $\mathrm{NH}_{2}$ and followed by thermal imidization. The prepared composite films were characterized by scanning electron microscopy (SEM), Fourier transform-infrared spectroscopy (FT-IR), thermal gravimetric analysis (TGA), differential scanning calorimeter (DSC), and tensile and elongation tests.

\section{MATERIALS AND METHODS}

\section{Reagents and Apparatus}

Carbon nanotube (multi-walled, purity 95\%, diameter: $10-15 \mathrm{~nm}$, length: 0.1-10 $\mu \mathrm{m}$, density: $1.7-2.1 \mathrm{~g} / \mathrm{cm}^{3}$ ) was purchased from Alfa Aesar. 4,4'-oxydianiline (ODA), thionyl chloride $\left(\mathrm{SOCl}_{2}\right)(\geq 99 \%), 3,3^{\prime}, 4,4^{\prime}$-benzophenone tetracarboxylic dianhydride (BTDA), (3-aminopropyl)trimethoxysilane (97\%), ethylenediamine and dimethylacetamide (DMAc) were purchased from Sigma Chem. Co. (St Louis, MO).

The structures of MWCNTs, in oxidized and amine-tethered forms, as well as polyamic acid and composite polyimides were investigated by Perkin Elmer ATR-FTIR spectrometer. The spectra were recorded in the frequency range of $4000-380 \mathrm{~cm}^{-1}$. The morphology of the composite polyimide films were investigated by scanning electron microscopy (SEM) on Phillips XL 30 ESEM-FEG/EDAX. Thermogravimetric analysis (TGA) was carried out on Perkin-Elmer Thermogravimetric analyzer STA 6000 at heating rate of $10{ }^{\circ} \mathrm{C} / \mathrm{min}$ from 30 to $750{ }^{\circ} \mathrm{C}$ in inert atmosphere. Differential scanning calorimeter studies were carried out on Pyris Diamond DSC (Perkin Elmer at a heating rate of 5 ${ }^{\circ} \mathrm{C} /$ min under $\mathrm{N}_{2}$. Mechanical properties of the composite films were analyzed by standard tensile stress-strain tests using a Zwick Z010universal tensile tester (Istanbul, Turkey).

\section{Synthesis of amine-tethered MWCNTs (MWCNT-NH ${ }_{2}$ )}

The modification of MWNCTs was carried out in three steps. At first, $1 \mathrm{~g}$ MWCNTs was refluxed in a mixture of sulfuric acid/nitric acid $(3: 1 \mathrm{v} / \mathrm{v})$ at $120^{\circ} \mathrm{C}$ for $4 \mathrm{~h}$. The mixture was diluted with deionized water $(2 \mathrm{~L})$ and filtered. The oxidized product was dried at 50 ${ }^{\circ} \mathrm{C}$. Then, the $\mathrm{COOH}$ groups of the oxidized MWCNTs were converted to acyl chloride ($\mathrm{COCl}$ ) groups with thionyl chloride at $70{ }^{\circ} \mathrm{C}$ for $24 \mathrm{~h}$. The unreacted thionyl chloride was removed by heating at $80^{\circ} \mathrm{C}$. The product was dried in vacuum. Finally, $0.5 \mathrm{~g}$ of acyl 
chloride functionalized MWCNTs was refluxed at $90^{\circ} \mathrm{C}$ for $24 \mathrm{~h}$ with ethylene diamine to prepare amine-tethered MWCNTs (15). The reaction pathway is shown in Figure 1.

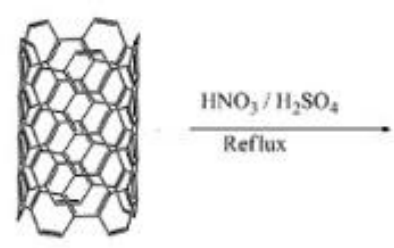

MWCNT
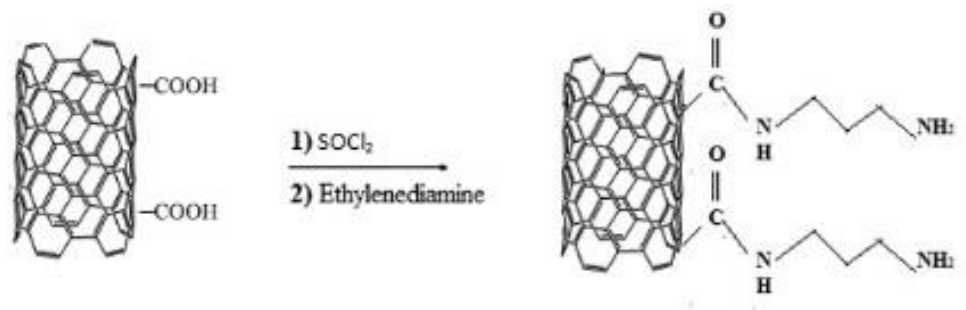

Oxidized MWCNT

Amine tethered MWCNT

Figure 1: Modification of multi-walled carbon nanotube.

\section{Preparation of BTDA-ODA Polyamic acid Solution}

The synthesis of the polyamic acid (PAA) precursor was followed according to literature (16). The solid concentration was afforded as a $20 \%(w t / v)$. Briefly, $9.011 \mathrm{~g}(0.045 \mathrm{~mol})$ of ODA was dissolved in $80 \mathrm{~mL}$ DMAc until obtaining a clear solution. Then, $9.815 \mathrm{~g}$ $(0.045 \mathrm{~mol})$ of BTDA was partially added and the mixture was stirred for $24 \mathrm{~h}$ at room temperature. Table 1 summarizes the preparation method of PAA solutions.

Table 1: Composition of polyamic acid solutions.

\begin{tabular}{llll}
\hline Codes & ODA (g) & BTDA (g) & Amine-tethered MWCNTs (\%) \\
\hline BTDA-ODA & 9.0108 & 9.8154 & - \\
BTDA-ODA-1\%MWCNTs & 9.0108 & 9.8154 & 1 \\
BTDA-ODA-3\% MWCNTs & 9.0108 & 9.8154 & 3 \\
BTDA-ODA-4\% MWCNTs & 9.0108 & 9.8154 & 4 \\
BTDA-ODA-5\% MWCNTs & 9.0108 & 9.8154 & 5 \\
BTDA-ODA-6\% MWCNTs & 9.0108 & 9.8154 & 6 \\
\hline
\end{tabular}

\section{Preparation of Amine-Tethered MWCNTs/Polyimide Films}

One of the following $(1,3,4,5$ or $6 \mathrm{wt} \%)$ amine-tethered MWCNTs were added to the PAA solution. The mixtures were sonicated for $10 \mathrm{~min}$ at room temperature and were cast on a glass substrate. Then, the glass substrate were dried stepwise at $80{ }^{\circ} \mathrm{C}, 100$ ${ }^{\circ} \mathrm{C}, 150{ }^{\circ} \mathrm{C}, 200{ }^{\circ} \mathrm{C}$ and $300{ }^{\circ} \mathrm{C}$ for $1 \mathrm{~h}$ at each temperature. The schematic fabrication process of amine-tethered MWCNTs/polyimide films is shown in Figure 2. The polyimides were obtained in $89-95 \%$ yield. The strong chemical bond between amino groups of CNTs-ODA and PI matrix. During the polymerization and thermal imidization process, amine-tethered MWCNT tended to form strong chemical bond with BTDA-ODA polyimide (17). The prepared products were washed with ethanol and dried under vacuum. 

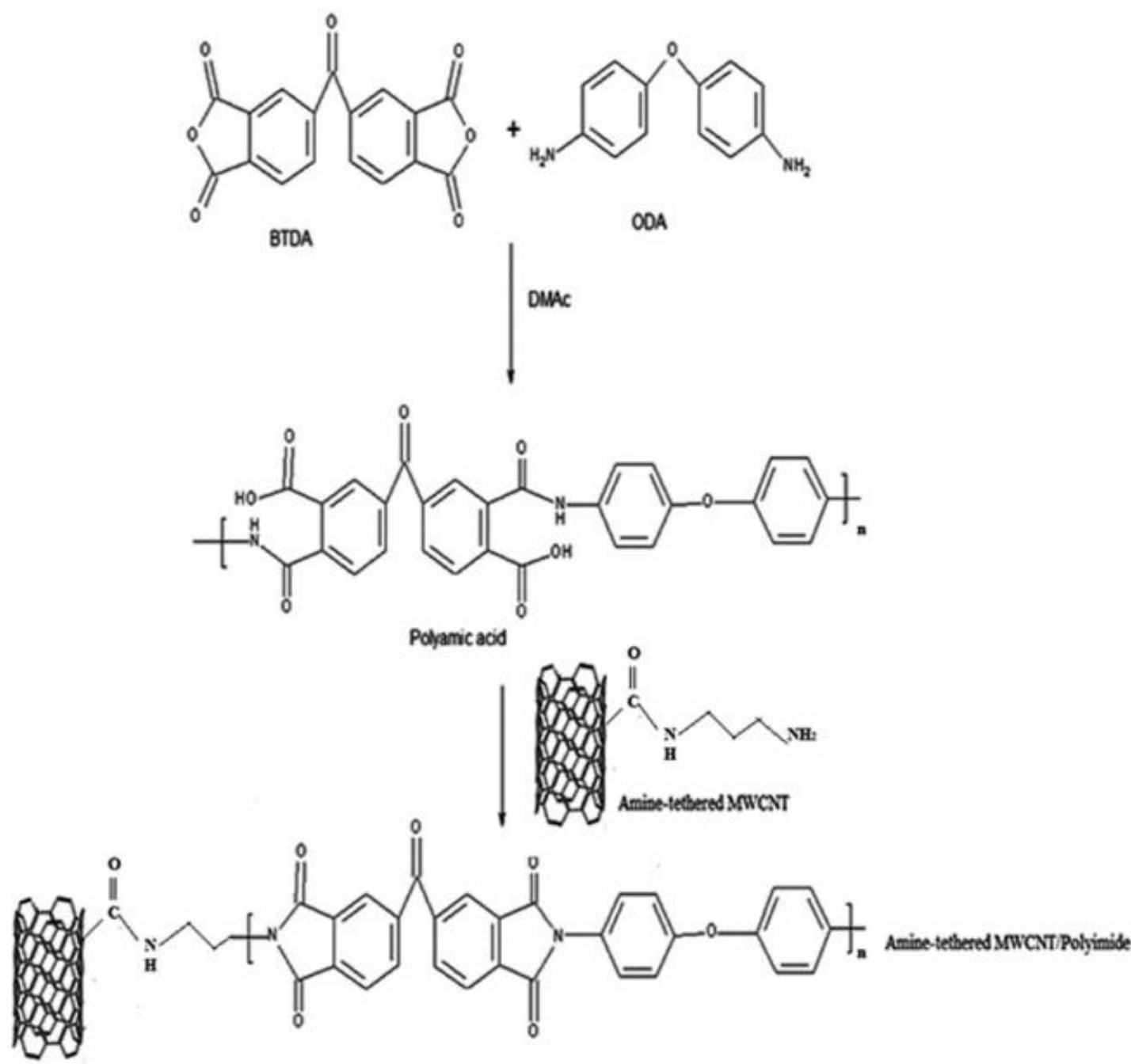

Figure 2: Preparation of amine-tethered MWCNTs/polyimide films.

\section{RESULTS}

\section{Characterization of MWCNTs- $\mathrm{NH}_{2}$}

Figure 3 shows the FTIR spectra of MWCNT, MWCNTs-COOH and MWCNTs- $\mathrm{NH}_{2}$. The band at $3700 \mathrm{~cm}^{-1}$ corresponds to free hydroxyl groups. The broad band in the range of $3400-$ $2800 \mathrm{~cm}^{-1}$ is associated to the characteristic O-H stretching from carboxyl groups in the oxidized MWCNTs $(\mathrm{O}=\mathrm{C}-\mathrm{OH}$ and $\mathrm{C}-\mathrm{OH})$. The peak at $1560 \mathrm{~cm}^{-1}$ is related to the carboxylate anion stretch mode (17). In the FTIR spectrum of the MWCNTs- $\mathrm{NH}_{2}$, the peak at $3200 \mathrm{~cm}^{-1}$ corresponds to the characteristic $\mathrm{N}-\mathrm{H}$ stretching of the CONH group. The $\mathrm{C}-\mathrm{H}$ stretching peaks at $2900 \mathrm{~cm}^{-1}$ and $2845 \mathrm{~cm}^{-1}$ indicate the covalent bonding of ethylene diamine on MWCNT. Evidently, as a result of the adsorption of CO on the MWCNT, broad bands in the $\mathrm{C}-\mathrm{O}$ stretch region appeared. Two bands at a frequency higher than the gas-phase CO frequency are found: A band around $2330 \mathrm{~cm}^{-1}$ and a band near $2108 \mathrm{~cm}^{-1}(19,20)$. 


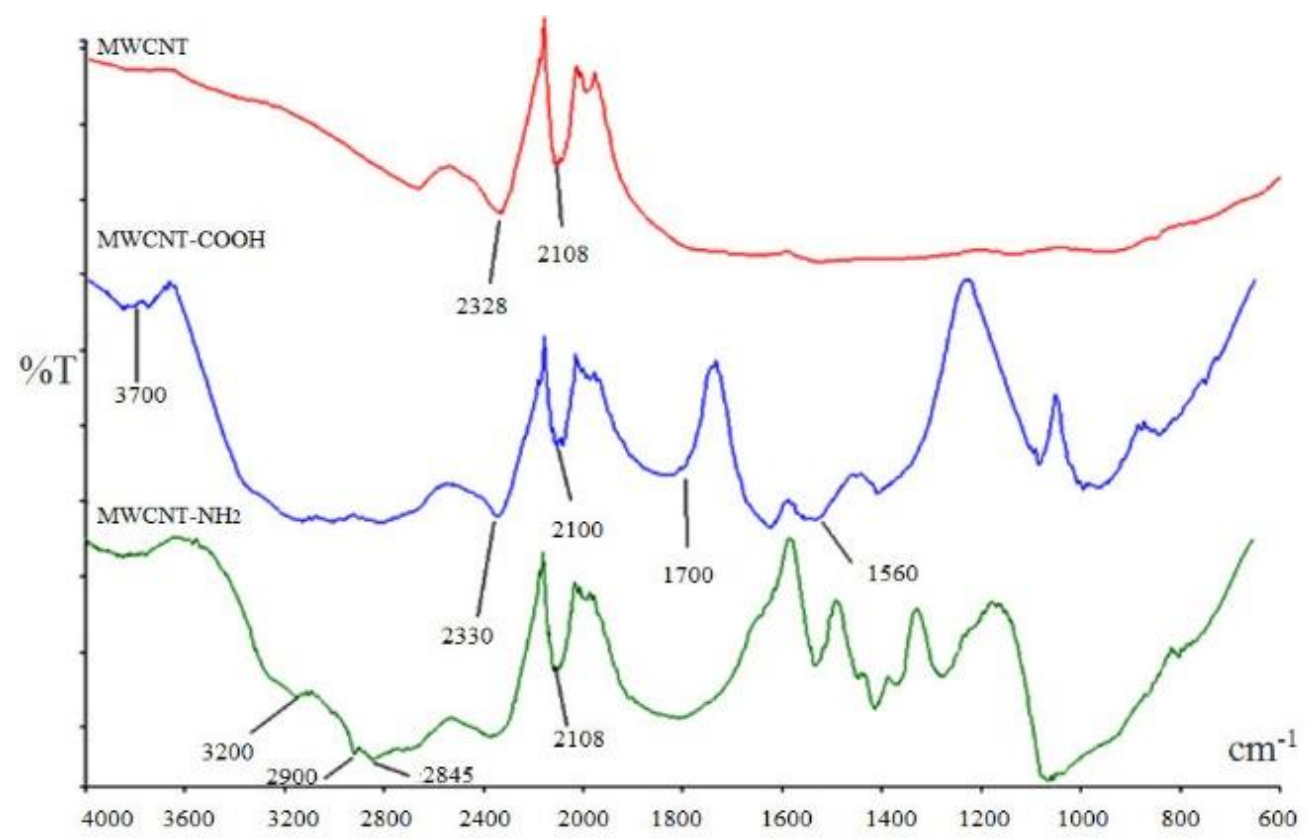

Figure 3: The FTIR spectra of MWCNT (in red), MWCNTs-COOH (in blue) and MWCNTs$\mathrm{NH}_{2}$ (in green).

\section{Structural Characterization of Polyimide Films}

Figure 4 shows the FTIR spectra of the polyamic acid and polyimide/MWCNTs films. In the spectrum of the polyamic acid (spectrum $A$ ), the characteristic amide band of polyamic acid is observed at $1617 \mathrm{~cm}^{-1}$. As can be seen from spectrum $B$ to $F$, the amide stretching peak disappeared after thermal imidization of polyamic acid solution. The absence of this peak indicates that imidization was successfully carried out. The new bands at 1777 and $1715 \mathrm{~cm}^{-1}$ correspond to asymmetric and symmetric carbonyl stretching of the polyimides, respectively. The stretching absorptions of - $\mathrm{C}-\mathrm{N}-\mathrm{C}-$ were observed at $1370 \mathrm{~cm}^{-1}$ and $1150 \mathrm{~cm}^{-1}$ (21). 


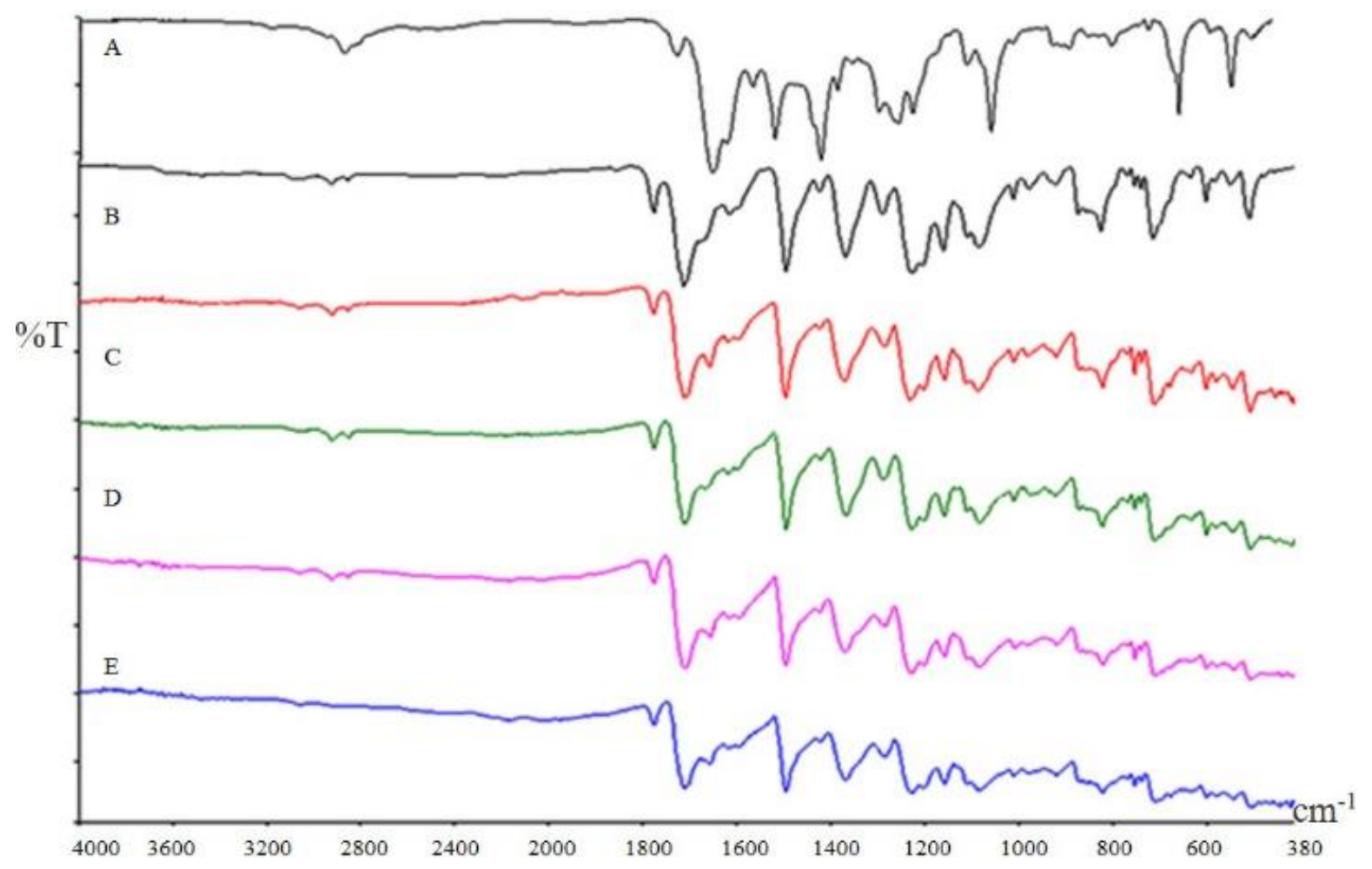

Figure 4: The FTIR spectra of the polyamic acid and polyimide/MWCNTs films. A)PAA, B) BTDA-ODA-\%1 MWCNTs, C) BTDA-ODA-\%3 MWCNTs, D) BTDA-ODA-\%4 MWCNTs, E) BTDA-ODA-\%5 MWCNTs and F) BTDA-ODA-\%6 MWCNTs

\section{Morphology of Polyimide films}

Morphology of the polyimide films were investigated by scanning electron microscopy (SEM). The SEM micrographs are shown in Figure 5a-d. Homogenous dispersion was obtained at a certain amount of MWCNTs as confirmed by SEM images. The aminetethered MWCNTs were dispersed in the polyimide matrix in individual tubes. Carbon nanotubes tend to agglomerate due to strong interfacial forces such as van der Waals interactions and geometry (22). To overcome the agglomeration of MWCNTs by modification is a critical challenge. Kim et al. reported that the strong interfacial interactions between modified MWCNTs with polyimide matrix take place by covalent and hydrogen bonds. In addition, the modification of MWCNTs provides the chemical compatibility between the PI matrix and the modified CNTs (23). The addition of MWCNT changed the morphology of polyimide. It is said that the surface roughness of films increased. 

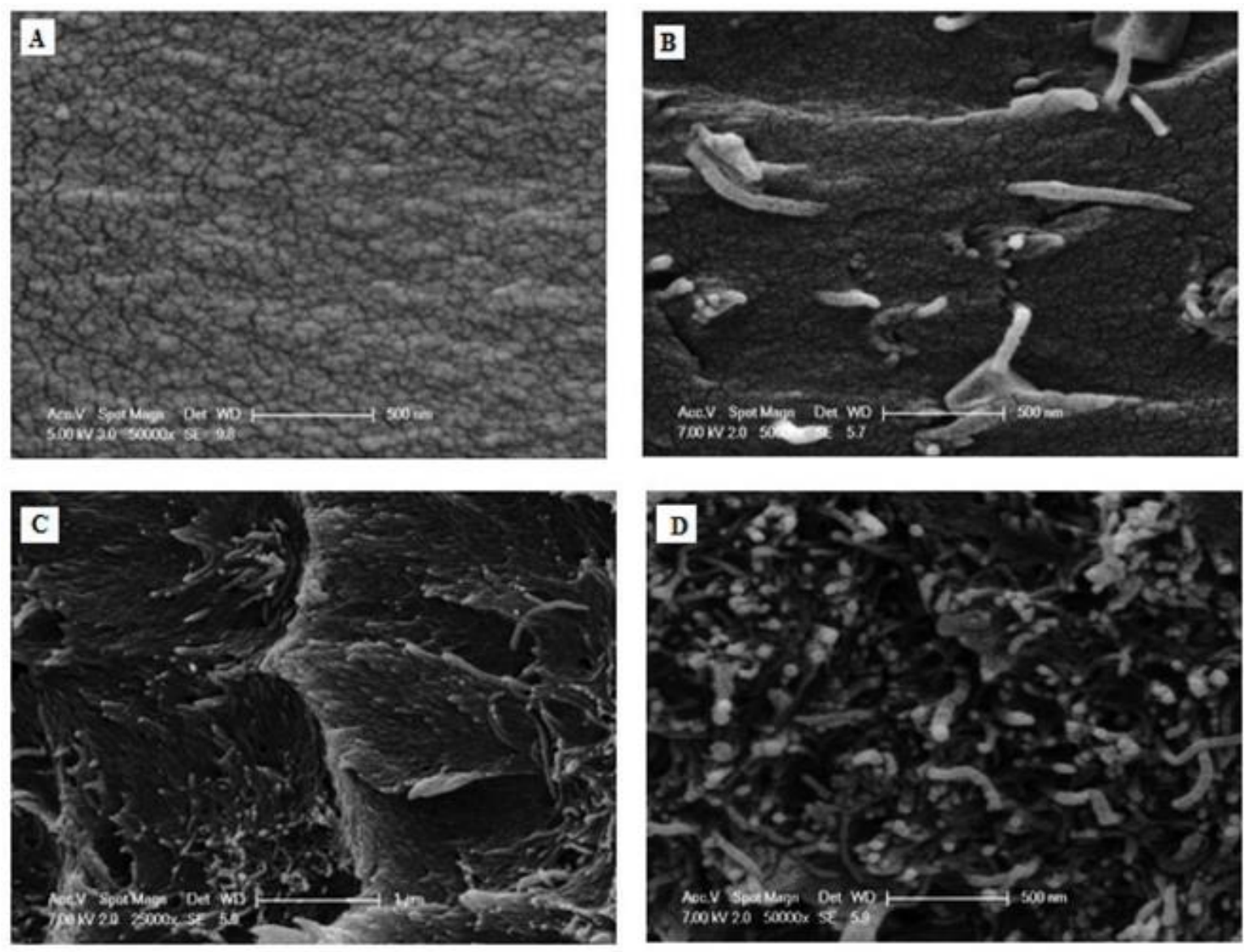

Figure 5: The SEM micrographs of (A) BTDA-ODA (50.000x), (B) BTDA-ODA-\%1 MWCNTs (50.000x), (C) BTDA-ODA-\%4 MWCNTs (25.000x) and (D) BTDA-ODA-\%6 MWCNTs (50.000x).

\section{Thermal properties of MWCTs/polyimide composite films}

Figure 6 shows TGA curves of neat polyimide and MWCTs/polyimide composite films. 5 $w t \%$ weight loss temperatures ( $T \% 5)$, maximum weight loss temperatures ( $\left.T_{\max } \%\right)$, and the residual char of the films are listed in Table 2. Aromatic polyimides exhibit high thermal stability because of their regular aromatic groups (24). The aromatic polyimides start to decompose after about $400{ }^{\circ} \mathrm{C}$ (25). As can be seen in Figure 6, TGA curves of the films exhibited one step degradation under nitrogen atmosphere. The maximum weight loss temperature ( $T_{\max }$ ) was found to slightly increase with increasing amount of modified-MWCNTs. It is known that MWCNTs make contribution to the thermal stability and decomposition rate (26). As expected, char yield of the polyimides gradually increased with addition of MWCNTs. 


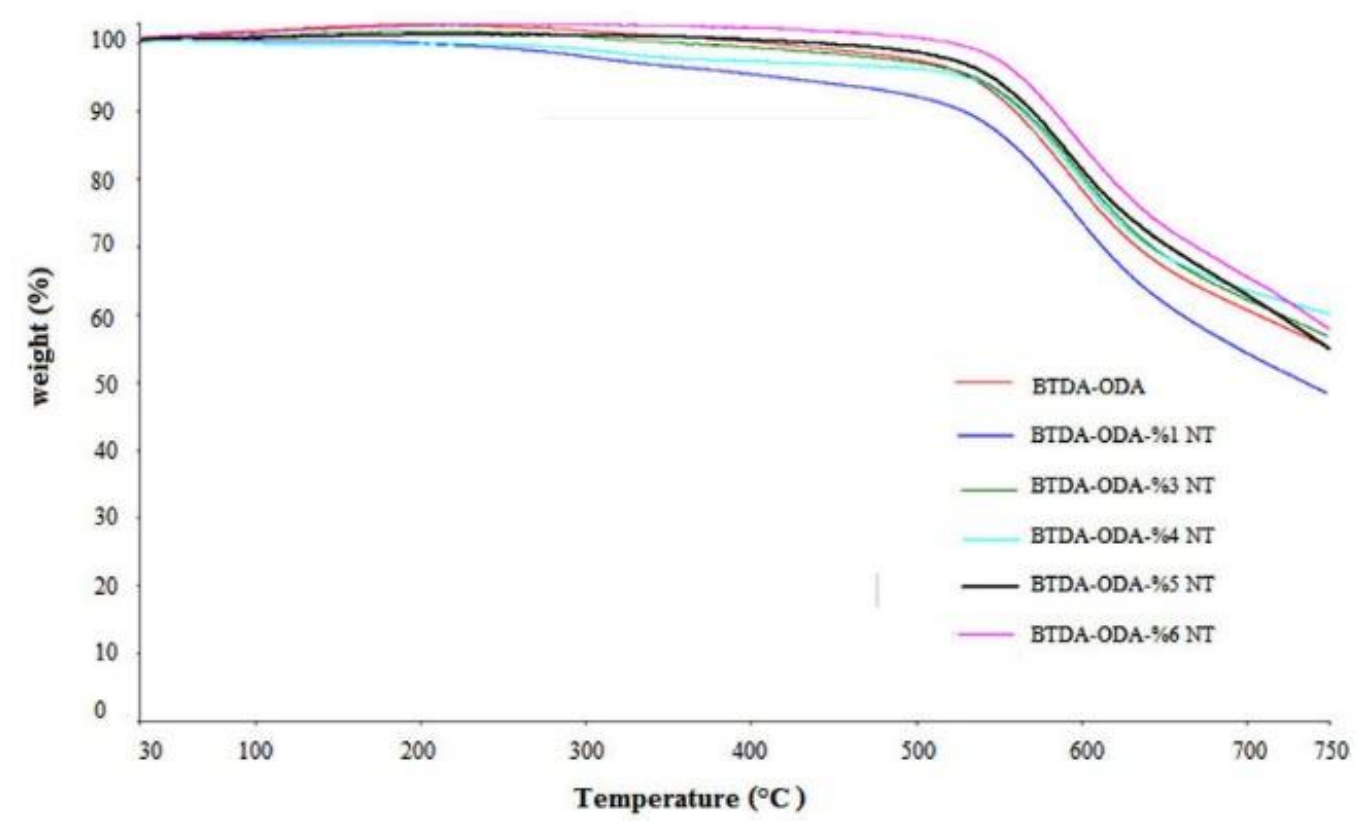

Figure 6: TGA thermograms of the BTDA-ODA polyimide and MWCNTs/Polyimide composite films in nitrogen atmosphere.

The glass transitions temperatures $(\mathrm{Tg})$ of polyimide films were investigated by differential scanning calorimeter. The $\mathrm{Tg}$ for BTDA-ODA polyimide film was $275^{\circ} \mathrm{C}$. DSC curves show that the addition of MWCNTs causes Tg values of the MWCTs/polyimide composite films to increase. The results are listed in Table 2 . The increasing $\mathrm{Tg}$ values demonstrated that amine modified MWCNTs were covalently bonded to the polyimide chains. The secondary network structure occurs by addition of MWCNTs to the BTDA-ODA crosslinked structure (27).

Table 2: Thermal and Mechanical properties of polyimide films.

\begin{tabular}{llllll}
\hline Codes & $\begin{array}{l}\mathbf{T \% 5}^{\circ} \\
\left(\mathbf{T}^{\circ} \mathbf{C}\right)\end{array}$ & $\begin{array}{l}\mathbf{T}_{\max } \\
\left(\mathbf{T}^{\circ} \mathbf{C}\right)\end{array}$ & $\begin{array}{l}\text { Char } \\
(\mathbf{\%})\end{array}$ & $\begin{array}{l}\mathbf{T g} \\
\left({ }^{\circ} \mathbf{C}\right)\end{array}$ & $\begin{array}{l}\text { E-modulus } \\
(\mathbf{M P a})\end{array}$ \\
\hline BTDA-ODA & 415 & 553 & 48.45 & 275 & 743 \\
BTDA-ODA-1\% MWCNTs & 535 & 603 & 55.33 & 277 & 1011 \\
BTDA-ODA-3\% MWCNTs & 528 & 555 & 56.00 & 280 & 1036 \\
BTDA-ODA-4\% MWCNTs & 531 & 565 & 60.10 & 287 & 1040 \\
BTDA-ODA-5\% MWCNTs & 544 & 571 & 54.76 & 289 & 1091 \\
BTDA-ODA-6\% MWCNTs & 563 & 590 & 57.56 & 304 & 1119 \\
\hline
\end{tabular}

\section{Mechanical properties of MWCTs/polyimide composite films}

The Young's modulus of the composite polyimide films are given in Table 2. The presence of MWCNTs increased the modulus of composite films compared to BTDA-ODA neat film. The modulus of BTDA-ODA polyimide film was found as $743 \mathrm{MPa}$. However, the modulus of the composite polyimide films increased with addition of amine-tethered MWCNTs. The modulus of BTDA-ODA-1\% MWCNT and BTDA-ODA-3\% MWCNT composite polyimide films were found as 1011 and $1036 \mathrm{MPa}$, respectively. Moreover, \%1, 2\%, 3\%, 4\%, 5\% 
and $6 \%$ MWCNTs containing polyimide films showed higher modulus than BTD-ODA polyimide film.

\section{CONCLUSIONS}

BTDA-ODA polyimide and BTDA-ODA-MWCNTs composite polyimide films were successfully prepared via in situ polymerization process. MWCNTs were functionalized with amine groups, to bond with the polyimide matrix. The addition of amine functionalized MWCNTs into a BTDA-ODA polyimide led to obvious improvements in the thermal and mechanical properties. SEM investigations indicate that MWCNTs were homogeneously dispersed in the polyimide matrix. The successful modification and attachment of MWCNTs into the polymeric matrix will create various applications for nanocomposite area.

\section{REFERENCES}

1. Yang F, Li Y, Zhang S, Tao M, Zhao J, Hang C. Functionalization of multiwalled carbon nanotubes and related polyimide/carbon nanotubes composites. Synthetic Metals 2010; (160), 15-16, : 18051808.

2. Olalde B, Aizpurua JM, García A, Bustero I, Obieta I, Jurado MJ. Single-Walled Carbon Nanotubes and Multiwalled Carbon Nanotubes Functionalized with Poly(I-lactic acid): a Comparative Study J. Phys. Chem. C. 2008; 112 (29): 10663-10667.

3. Meng L, Fu C , Lu Q. Advanced technology for functionalization of carbon nanotubes Progress in Natural Science. 2009; (19), 7- 10: 801-810.4. J Nanomater, 83583 (2006), pp. 1-5.

4.Z.M. Dang, L. Wang, L.P. Zhang Surface functionalization of multiwalled carbon nanotube with trifluorophenyl. J Nanomater. 2006; (83583): 1-5.

5. Oktay B, Toker RD, Kayaman-Apohan N. Superhydrophobic behavior of polyimide-siloxane mats produced by electrospinning. Polymer Bulletin. 2015: (72), 11; 2831-2842.

6. Srivastava R, Banerjee S, Jehnichen D, Voit B, Böhme F. In Situ Preparation of Polyimide/AminoFunctionalized Carbon Nanotube Composites and Their B Properties. Macromol. Mater. Eng. 2009; (294): 96-102.

7. Park C, Ounaies Z, Watson KA, Crooks RE, Smith JE, Lowther SE. Dispersion of single wall carbon nanotubes by in situ polymerization under sonication. Chem. Phys. Lett. 2002;(364):303-8.

8. Zhu BK, Xie SH, Xu ZK, Xu YY. Preparation and properties of the polyimide/multi-walled carbon nanotubes (MWNTs). Compos Sci Technol 2006;(66):548-554.

9. So HH, Cho Sahoo NG. Effect of carbon nanotubes on mechanical and electrical properties of polyimide/carbon nanotubes nanocomposites. Macromolecular Nanotechnology. European Polymer Journal. 2007; (43): 3750-3756.

10. Li R, Wang $X$, Ji Z, Sun B, Zhang $H$, Chang $C H$, et al. Surface Charge and Cellular Processing of Covalently Functionalized Multiwall Carbon Nanotubes Determine Pulmonary Toxicity. ACS Nano. $2013 \operatorname{Mar} 26 ; 7(3): 2352-68$.

11. Kim SW, Kim T, Kim YS, Choi HS, Lim HJ, Yang SJ, et al. Surface modifications for the effective dispersion of carbon nanotubes in solvents and polymers. Carbon. 2012 Jan;50(1):3-33. 
12. Murugesan S, Myers K, Subramanian V (Ravi). Amino-functionalized and acid treated multiwalled carbon nanotubes as supports for electrochemical oxidation of formic acid. Applied Catalysis B: Environmental. $2011 \mathrm{Apr} ; 103(3-4): 266-74$.

13. Xie H, Sheng C, Chen X, Wang X, Li Z, Zhou J. Multi-wall carbon nanotube gas sensors modified with amino-group to detect low concentration of formaldehyde. Sensors and Actuators B: Chemical. 2012 Jun;168:34-8.

14. Mugadza T, Nyokong T. Covalent linking of ethylene amine functionalized single-walled carbon nanotubes to cobalt (II) tetracarboxyl-phthalocyanines for use in electrocatalysis. Synthetic Metals. 2010 Oct; 160(19-20):2089-98.

15. Vatanpour V, Safarpour M, Khataee A, Zarrabi H, Ehsan M, Kavian YM. A thin film nanocomposite reverse osmosis membrane containing amine-functionalized carbon nanotubes. Separation and Purification Technology. 2017: (184), 31; 135-143

16. Çakmakçı E, Güngör A. Preparation and characterization of flame retardant and proton conducting boron phosphate/polyimide composites. Polymer Degradation and Stability. 2013; (98), 5: $927-933$.

17. Wang J, Jiao Q, Li H, Zhao Y, Guo B. In situ preparation of polyimide/amino-functionalized carbon nanotube composites and their properties. Polymer Composites. 2014 Oct;35(10):1952-9.

18. Atieh MA, Bakather OY, Al-Tawbini B, Bukhari AA, Abuilaiwi FA, Fettouhi MB. Effect of Carboxylic Functional Group Functionalized on Carbon Nanotubes Surface on the Removal of Lead from Water. Bioinorg Chem Appl. 2011:(2010); 2010: 603978.

19. Jucureanu V, Matei A, Avram AM. FTIR Spectroscopy for Carbon Family Study. Critical Reviews in Analytical Chemistry. 2016 Nov;46(6):502-20.

20. V. Rakíc, V. Dondur, R. Hercigonja. FTIR study of carbon monoxide adsorption on ionexchanged X, Y and mordenite type zeolites. Journal of the Serbian Chemical Society. 2003: (4-5): 409-16.

21. So HH, Cho JW, Sahoo NG. Effect of carbon nanotubes on mechanical and electrical properties of polyimide/carbon nanotubes nanocomposites. European Polymer Journal. 2007: (43), 9:7503756.

22. Wang J, Pui DYH. Dispersion and Filtration of Carbon Nanotubes (CNTs) and Measurement of Nanoparticle Agglomerates in Diesel Exhaust. Chem Eng Sci. 2013: (85); 69-76.

23. Kim BS, Bae SH, Park YH, Kim JH. Preparation and Characterization of Polyimide/CarbonNanotube Composites. Macromolecular Research, 2007 (15),4: 357-362.

24. Ha CS., Mathews A.S. (2011) Polyimides and High Performance Organic Polymers. In: Advanced Functional Materials. Springer, Berlin, Heidelberg.

25. Ribeiro CR, Freeman BD, Kalika DS, Kalakkunnath S. Pervaporative Separation of Aromatic/Aliphatic Mixtures with Poly(Siloxane-co-Imide) and Poly(Ether-co-Imide) Membranes. Ind Eng Chem Res 2013; (52): 8906-8916.

26. Mahajan A, Ákos AK, Zoltan K, Vilarinho PM. Studies on the thermal decomposition of multiwall carbon nanotubes under different atmospheres. Materials Letters. 2013; (90),1:165-168.

27. Mo TC, Wang HW, Chen SY, Yeh YC. Synthesis and Characterization of Polyimide/ Multi-Walled Carbon Nanotube nanocomposites. Polymer Composites. 2008; (29), 4: 451-457. 
